\title{
GSK343 induces autophagy and downregulates the AKT/mTOR signaling pathway in pancreatic cancer cells
}

\author{
HAO XU ${ }^{1,2^{*}}$, LINSHI ZHANG ${ }^{1,2^{*}}$, XIAOHUI QIAN ${ }^{1,2}$, XIAOHU ZHOU $^{1,2}$, YINGCAI YAN $^{1,2}$, \\ JIARONG ZHOU ${ }^{1,2}$, WENHAO GE ${ }^{1,2}$, MUGAHED ALBAHDE ${ }^{1,2}$ and WEILIN WANG ${ }^{1-3}$
}

\begin{abstract}
${ }^{1}$ Department of Hepatobiliary and Pancreatic Surgery, The Second Affiliated Hospital, School of Medicine, Zhejiang University; ${ }^{2}$ Key Laboratory of Precision Diagnosis and Treatment for Hepatobiliary and Pancreatic Tumor of Zhejiang Province; ${ }^{3}$ Clinical Research Center of Hepatobiliary and Pancreatic Diseases of Zhejiang Province, The First Affiliated Hospital, School of Medicine, Zhejiang University, Hangzhou, Zhejiang 310009, P.R. China
\end{abstract}

Received September 14, 2018; Accepted July 8, 2019

DOI: $10.3892 / \mathrm{etm} .2019 .7845$

\begin{abstract}
Pancreatic cancer is a common malignancy that has a poor prognosis and limited therapeutic options. Enhancer of zeste homolog 2 (EZH2) serves a key role in the progression of different types of cancers. The effect of GSK343 (a competitive inhibitor of EZH2) on pancreatic cancer cells was assessed in the present study. Cell viability was evaluated using MTT and cell counting kit-8 assays in AsPC-1 and PANC-1 cells. Flow cytometry and an EdU assay were also performed to assess the effects of GSK343 on cell proliferation, apoptosis and the cell cycle. The induction of autophagy and associated molecular mechanisms were studied using fluorescence microscopy and western blot analysis. The results demonstrated that GSK343 inhibited cell viability in a dose- and time-dependent manner. Furthermore, GSK343 suppressed cell proliferation, promoted apoptosis and blocked cell cycle progression at the G1-phase. Furthermore, GSK343 induced autophagy in pancreatic cancer via the AKT/mTOR signaling pathway. In conclusion, GSK343 exhibited an anti-cancer effect on pancreatic cancer cells, downregulating the AKT/mTOR signaling pathway.
\end{abstract}

\section{Introduction}

Pancreatic cancer is a common malignancy with a poor prognosis. According to predictions by the American Cancer Society, 56,770 new pancreatic carcinoma diagnoses will be made in 2019 and as such, will become the fourth-highest

Correspondence to: Dr Weilin Wang, Department of Hepatobiliary and Pancreatic Surgery, The Second Affiliated Hospital, School of Medicine, Zhejiang University, 88 Jiefang Road, Hangzhou, Zhejiang 310009, P.R. China

E-mail:wam@zju.edu.cn

*Contributed equally

Key words: enhancer of zeste homolog 2, GSK343, autophagy, AKT/mTOR pathway, pancreatic cancer cause of mortality in the US (with rates as high as $80 \%$ ), irrespective of sex (1). It is also estimated that pancreatic cancer will surpass liver cancer in becoming the second-highest cause of cancer-associated deaths by 2030 (2). Due to the clinically vague nature of early stage disease, the majority of pancreatic cancer diagnoses are only possible after metastasis at more advanced stages (3). Due to pancreatic cancer exhibiting high chemotherapy and radiation therapy resistance, surgical resection is the only effective therapeutic option currently available (3). Novel strategies for treating pancreatic cancer are therefore urgently required.

Enhancer of zeste homolog 2 (EZH2) is the enzymatically active subunit of polycomb repressive complex 2 , which catalyzes the trimethylation of lysine 27 on histone 3 (H3K27) by transferring a methyl group from S-adenosyl-L-methionine (SAM), leading to the transcriptional silencing of target genes $(4,5)$. Although the underlying molecular mechanism of EZH2 oncogenic activity is unclear, EZH2 has been revealed to serve a key role in the progression of different types of cancer, including prostate cancer, breast cancer, endometrial cancer, melanoma and hematological malignancies (6-14). A previous study demonstrated that there was a high expression of EZH2 in pancreatic cancer cells and tissues, which was associated with proliferation, invasion and chemoresistance (15). EZH2 overexpression may also be a promising prognostic marker for patients with pancreatic cancer after surgery (16).

GSK343 serves as a SAM-competitive inhibitor, exerting an enzymatically repressive function on EZH2 (17). This is distinct from 3-deazaneplanocin A (DZNep), which inhibits the activity of S-adenosyl-L-homocystenine hydeolase (SAH) (18). Numerous studies have reported an elevated expression of EZH2 in various types of cancer, which is associated with a poor prognosis and metastasis (19-23). The inhibition of EZH2 has been regarded as a novel therapeutic target for various carcinomas (24-28).

The current study aimed to elucidate the effects of GSK343 on pancreatic cancer cells to determine a potential future putative therapeutic strategy. The results of the present study revealed that GSK343 may be a potential anti-cancer drug and may exert an autophagy-inducing effect. 


\section{Materials and methods}

Materials. GSK343 (cat. no. S7164; Selleck Chemicals) was dissolved in $5 \mathrm{mmol} / \mathrm{l}$ DMSO. Primary antibodies against GAPDH (cat. no. 60004-1-Ig; ProteinTech Group, Inc.), microtubule-associated protein 1 light chain 3 beta (LC3B; cat. no. L7543; Sigma-Aldrich; Merck KGaA), AKT (cat. no. 1085; Abcam), phospho-AKT (cat. no. 2118; Abcam), autophagy-related protein 5 (ATG5; cat. no. 12994; Cell Signaling Technology, Inc.), mTOR (cat. no. 2983; Cell Signaling Technology, Inc.) and phospho-mTOR (cat. no. 5536; Cell Signaling Technology, Inc.). Horseradish peroxidase-conjugated anti-rabbit secondary antibodies (cat. no. A00098; GenScript) or anti-mouse (cat. no. A00160; GenScript) and fluorochrome-conjugated anti-rabbit secondary antibodies (cat. no. E031220; EarthOx Life Sciences) were used at the recommended concentrations outlined by the manufacturer's protocol.

Cell culture. A primary cancer cell was randomly selected (PANC-1, derived from pancreatic ductal epithelial cells) and a metastatic cancer cell line (AsPC-1, ascites metastasis) was used in the present study to clarify the function of GSK343 (all, American Type Culture Collection). The two pancreatic cell lines were cultured in RPMI 1640 medium (Thermo Fisher Scientific, Inc.) supplemented with 10\% FBS (Sigma-Aldrich; Merck $\mathrm{KGaA}$ ) and incubated at $37^{\circ} \mathrm{C}$ with $5 \% \mathrm{CO}_{2}$.

MTT assay. AsPC-1 and PANC-1 Cells were plated into 96-well plates $\left(3 \times 10^{3}\right.$ cells/well $) 24 \mathrm{~h}\left(37^{\circ} \mathrm{C} ; 5 \% \mathrm{CO}_{2}\right)$ prior to treatment with various concentrations $(0,2.5,5.0,7.5,10.0$, $12.5,15,17.5,20$ and $25 \mu \mathrm{mol} / \mathrm{l})$ of GSK343 for an additional $48 \mathrm{~h}$ at $37^{\circ} \mathrm{C}$ with $5 \% \mathrm{CO}_{2}$. A total of $5 \mathrm{mg} / \mathrm{ml}$ of MTT (Beijing Solarbio Science \& Technology Co., Ltd.) was added into each well for an additional $4 \mathrm{~h}$ at $37^{\circ} \mathrm{C}$ with $5 \% \mathrm{CO}_{2}$. The purple MTT formazan precipitate was dissolved in $200 \mu \mathrm{l}$ DMSO and the absorption value was measured using a spectrophotometer at $570 \mathrm{~nm}$. Curves were fitted and analyzed with GraphPad software version 6.0 to calculate the IC50 value (GraphPad Software, Inc.).

Cell counting kit-8 (CCK-8) assay. AsPC-1 and PANC-1 cells were seeded at a density of $3 \times 10^{3}$ cells per well into 96-well plates $24 \mathrm{~h}\left(37^{\circ} \mathrm{C} ; 5 \% \mathrm{CO}_{2}\right)$ prior to treatment with the IC50 concentration of GSK343 $(12.71 \mu \mathrm{mol} / \mathrm{l}$ for AsPC-1, $12.04 \mu \mathrm{mol} / 1$ for PANC-1) at $37^{\circ} \mathrm{C}$ with $5 \% \mathrm{CO}_{2}$ for 0,24 , 48 and $72 \mathrm{~h}$. A total of $10 \mu \mathrm{l} \mathrm{CCK-8} \mathrm{(Dojindo} \mathrm{Molecular}$ Technologies, Inc.) was subsequently added to each well for an additional $2 \mathrm{~h}$ at $37^{\circ} \mathrm{C}$ with $5 \% \mathrm{CO}_{2}$, and optical density $\left(\mathrm{OD}_{450}\right)$ was measured using a multi-well plate reader.

EdU viability assay. A Cell-Light ${ }^{\mathrm{TM}}$ EdU Apollo567 In Vitro Imaging kit (Guangzhou RiboBio Co., Ltd.) was used to evaluate the effect of GSK343, according to the manufacturer's protocol. Following treatment with IC50 concentration of GSK343 (12.71 $\mu \mathrm{mol} / 1$ for AsPC-1; $12.04 \mu \mathrm{mol} / 1$ for PANC-1) and $20 \mu \mathrm{mol} / \mathrm{l}$ of GSK343 for $48 \mathrm{~h}$, the proportion of AsPC-1 and PANC-1 cells that incorporated EdU, was observed using a fluorescence microscope (Olympus IX71; Olympus Corporation; magnification, $\mathrm{x} 200$ ).
Flow cytometry analysis. For the analysis of apoptosis, AsPC-1 and PANC-1 cells were seeded at a density of $2 \times 10^{5}$ cells per well in six-well plates. Cells of $\mathrm{NC}$ group were treated with $8 \mu \mathrm{l}$ DMSO per well. After treatment with IC50 concentration of GSK343 $(12.71 \mu \mathrm{mol} / 1$ for AsPC-1; $12.04 \mu \mathrm{mol} / 1$ for PANC-1) and $20 \mu \mathrm{mol} / 1$ of GSK343, cells were harvested and double stained with $5 \mu$ l Annexin V-FITC and $5 \mu$ l PI (Annexin V, FITC Apoptosis Detection kit; cat. no. AD10; Dojindo Molecular Technologies, Inc.) in the dark. For the assessment of cell cycle distribution, cells were collected and fixed in $75 \%$ ethanol overnight at $4{ }^{\circ} \mathrm{C}$ after treatment with GSK343 for $48 \mathrm{~h}$. Upon completion of treatment, cells were washed with PBS and resuspended in $500 \mu \mathrm{l}$ of staining solution (Cell Cycle Staining kit; cat. no. CCS012; Hangzhou Multi Sciences Biotech Co., Ltd.) at $37^{\circ} \mathrm{C}$ for $30 \mathrm{~min}$. Finally, apoptosis and cell cycle distribution were detected using flow cytometry (CYTOMICS FC 500; Beckman Coulter, Inc.). Flowjo software 7.6.1 (FlowJo LLC) and Modifit LT software 3.1 (Verity Software House, Inc.) were used to analyze the data of apoptosis and cell cycle.

Immunofluorescence microscopy. After treatment with IC50 concentration of GSK343 (12.71 $\mu \mathrm{mol} / 1$ for AsPC-1; $12.04 \mu \mathrm{mol} / 1$ for PANC-1) for $48 \mathrm{~h}$, AsPC-1 and PANC-1 cells were fixed in $100 \%$ methanol for $10 \mathrm{~min}$ at $-20^{\circ} \mathrm{C}$, washed with PBST, blocked using $10 \% \mathrm{FBS}$ at $37^{\circ} \mathrm{C}$ for $1 \mathrm{~h}$ and subsequently incubated with rabbit polyclonal antibody against LC3B, which includes LCBI and LC3BII (1:100) overnight at $4^{\circ} \mathrm{C}$. Fluorochrome-conjugated anti-rabbit $\operatorname{IgG}(1: 100)$ was added to slides and incubated at $37^{\circ} \mathrm{C}$ for $1 \mathrm{~h}$, after which DAPI counterstaining was performed at $37^{\circ} \mathrm{C}$ for $20 \mathrm{~min}$ and observations were made using a fluorescence microscope (Olympus IX71; magnification, $\mathrm{x} 400$ ).

Western blot analysis. Western blotting was performed as previously described (29). AsPC-1 and PANC-1 cells were harvested and dissolved in a $100 \mu \mathrm{l}$ mixture of radioimmunoprecipitation assay lysis buffer (Beyotime Institute of Biotechnology, Inc.) and complete protease inhibitor cocktail (Roche Diagnostics) for $30 \mathrm{~min}$ so that total protein could be extracted. Protein concentration was then measured using a BCA protein assay kit (cat. no. 23250; Thermo Fisher Scientific, Inc.). Equal quantities of protein $(20 \mu \mathrm{g})$ were subsequently separated on 10\% NuPAGE Bis-Tris gels (Invitrogen; Thermo Fisher Scientific, Inc.) for electrophoresis and transferred to $0.45 \mu \mathrm{m}$ PVDF membranes for $60 \mathrm{~min}$. Membranes were then blocked using $5 \%$ non-fat milk at $37^{\circ} \mathrm{C}$ for $1 \mathrm{~h}$ and incubated with primary antibodies against GAPDH, LC3B, AKT, phospho-AKT, ATG5, mTOR and phospho-mTOR at 1:1,000 overnight at $4^{\circ} \mathrm{C}$. Membranes were then incubated with horseradish peroxidase-conjugated anti-rabbit or anti-mouse secondary antibodies at 1:2,000 for $1 \mathrm{~h}$ at room temperature and protein bands were detected using enhanced chemiluminescence (cat. no. G2014; Wuhan Servicebio Technology Co., Ltd.). Band intensity of LC3B-I and LC3B-II was quantified using Image Lab software 5.2.1 (Bio-Rad Laboratories, Inc.).

Statistical analysis. Data were analyzed using SPSS software 24 (IBM Corp.) and figures were created using GraphPad software 6.0 (GraphPad Software, Inc.). The results were 


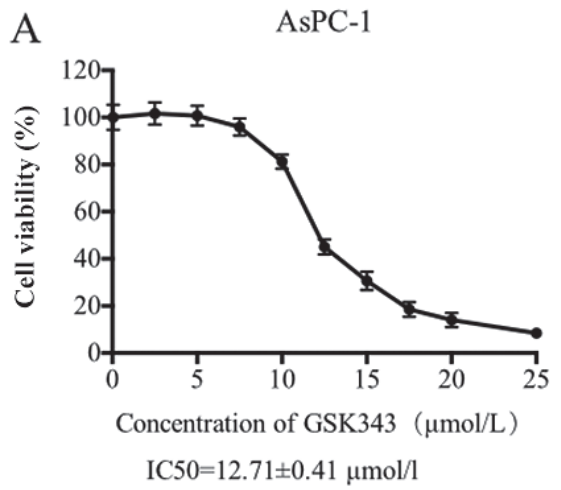

B

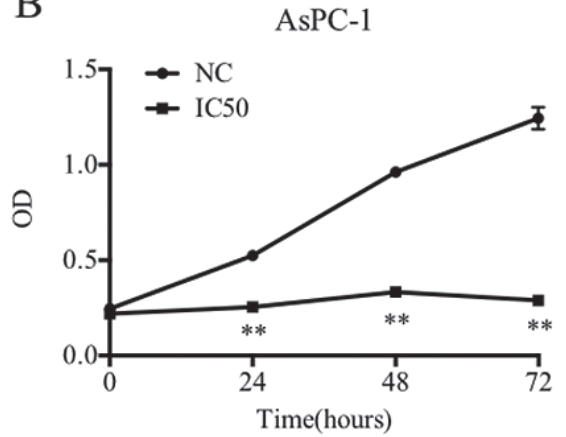

PANC-1

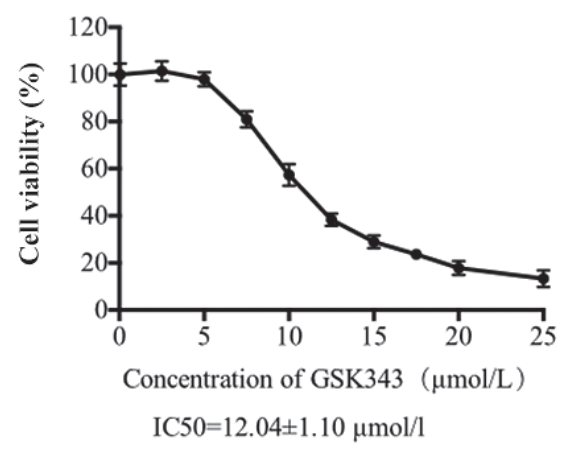

PANC-1

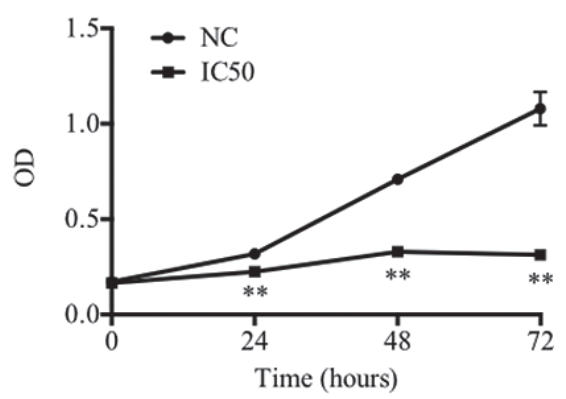

Figure 1. Effects of GSK343 on AsPC-1 and PANC-1 cell viability. (A) MTT analysis of cell viability after treatment with different concentrations of GSK343 for 48 h. (B) Cell counting kit-8 analysis of cell growth after treatment with GSK343 (IC50) for 0, 24, 48 and $72 \mathrm{~h},{ }^{* * *} \mathrm{P}<0.01$. NC, negative control; OD, optical density.

expressed as the mean \pm standard deviation from three independent experiments. A one-way ANOVA was performed followed by a Tukey HSD post-hoc test to make comparisons between multiple groups. Comparisons between two groups were analyzed using a Student's t-test. $\mathrm{P}<0.05$ was considered to indicate a statistically significant result.

\section{Results}

GSK343 inhibits cell viability and suppresses cell proliferation. GSK343, an inhibitor of EZH2, has been regarded to be a therapeutic target for various types of cancer. In the present study, the effect of GSK343 on the viability of pancreatic cancer cells (AsPC-1 and PANC-1) was evaluated using an MTT assay. As presented in Fig. 1A, the viability of each pancreatic cancer cell line markedly decreased with increasing GSK343 concentration. The IC50 values of AsPC-1 and PANC-1 $(12.71 \pm 0.41$ and $12.04 \pm 1.10 \mu \mathrm{mol} / \mathrm{l})$ revealed that neither pancreatic cell line exhibited a statistically significant difference between values.

The IC50 was selected as a suitable concentration for pancreatic cancer cell treatment and viability after incubation with GSK343 for 24, 48 and $72 \mathrm{~h}$ using a CCK-8 assay. As presented in Fig. 1B, compared with NC, GSK343 (IC50) significantly reduced the OD values from 24 to $72 \mathrm{~h}$. The difference values were gradually increased, which revealed that GSK343 may inhibit cell viability in AsPC-1 and PANC-1 cells in a time-dependent manner.

To demonstrate the effects of GSK343 on cell proliferation, an EdU assay was performed using AsPC-1 and PANC-1 cells after treatment with the IC50 for the respective cell lines and
$20 \mu \mathrm{mol} / \mathrm{l}$ of GSK343 for $48 \mathrm{~h}$. The percentage of EdU-positive cancer cells (in AsPC-1 and PANC-1 lines) decreased markedly after treatment with GSK343 (Fig. 2). Therefore, GSK343 suppressed the proliferation of pancreatic cancer cells in a dose-dependent manner.

GSK343 induces cell apoptosis and G1 arrest. To determine the underlying mechanisms that result in the loss of cell viability and the suppression of cell proliferation, apoptosis and cell cycle distribution were assessed using flow cytometry. AsPC-1 and PANC-1 were treated with different concentrations of GSK343 ( $0 \mu \mathrm{mol} / 1$; IC50 for the respective cell lines; $20 \mu \mathrm{mol} / \mathrm{l})$.

As presented in Fig. 3, the Annexin V-FITC/PI assay results reveal that GSK343 treatment induces significant cell apoptosis compared with the untreated pancreatic cancer cells. One representative result was selected, which is presented in Fig. 3A. In AsPC-1 cells, the IC50 dose and $20 \mu \mathrm{mol} / 1$ of GSK343 increased the percentage of apoptotic cells from 6.86 to 13.31 and $20.11 \%$, respectively. The percentage of PANC-1 apoptotic cells after treatment with GSK343, the IC50 concentration and $20 \mu \mathrm{mol} / 1$ increased from 2.88 to 9.74 and $17.85 \%$, respectively.

In Fig. 4, following GSK343 treatment, an increase in the percentage of cells in G1-phase and a reduction in S-phase cells was observed in AsPC-1 and PANC-1 cells. The IC50 of GSK343 increased the percentage of AsPC-1 and PANC-1 cells in G1-phase from 39.78 to $64.14 \%$ and 42.02 to $62.59 \%$ (Fig. 4A), respectively. GSK343 (IC50) also reduced the percentage of AsPC-1 and PANC-1 cells in S-phase from 45.15 to $22.32 \%$ and 40.94 to $25.03 \%$ (Fig. 4A). A concentration of $20 \mu \mathrm{mol} / 1$ of GSK343 decreased the percentage of 

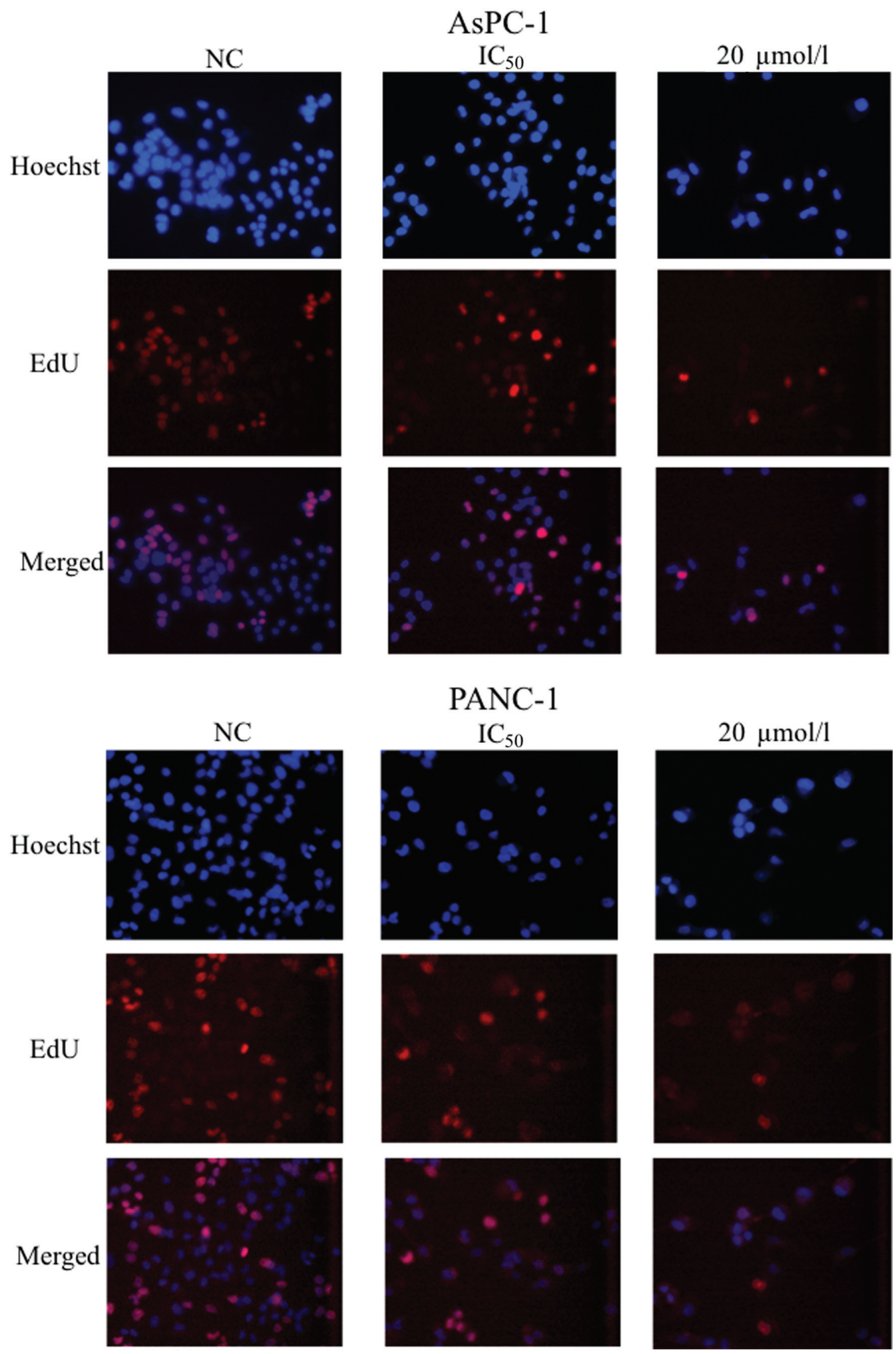

zure 2. GSK343 suppressed the proliferation of AsPC-1 and PANC-1 cells. Blue channels represent cell nuclei and red channels represent proliferating cells. After treatment with $0 \mu \mathrm{mol} / 1$, IC50, or $20 \mu \mathrm{mol} / 1 \mathrm{GSK} 343$ for $48 \mathrm{~h}$, the proportion of pancreatic cancer cells incorporating EdU was observed under a fluorescence microscope (magnification, x200).

AsPC-1 in the G2-phase from 15.07 to $5.44 \%$ (Fig. 4A). In Fig. 4B, compared with the NC, the IC50 concentration and $20 \mu \mathrm{mol} / \mathrm{l}$ group exhibited significantly increased percentages of G1-phase cells. However, $20 \mu \mathrm{mol} / 1$ of GSK343 did not lead to an increase of pancreatic cancer cells in the G1 phase compared with the IC50 concentration.
GSK343 induces autophagy in pancreatic cancer cells. Autophagy is a process in which cytoplasmic proteins and organelles are delivered to the lysosome for digestion. Various studies have reported the induction of autophagy by GSK343 in osteosarcoma cells, as well as in breast, liver and colorectal cancer (30-32). Autophagy induction was analyzed using 

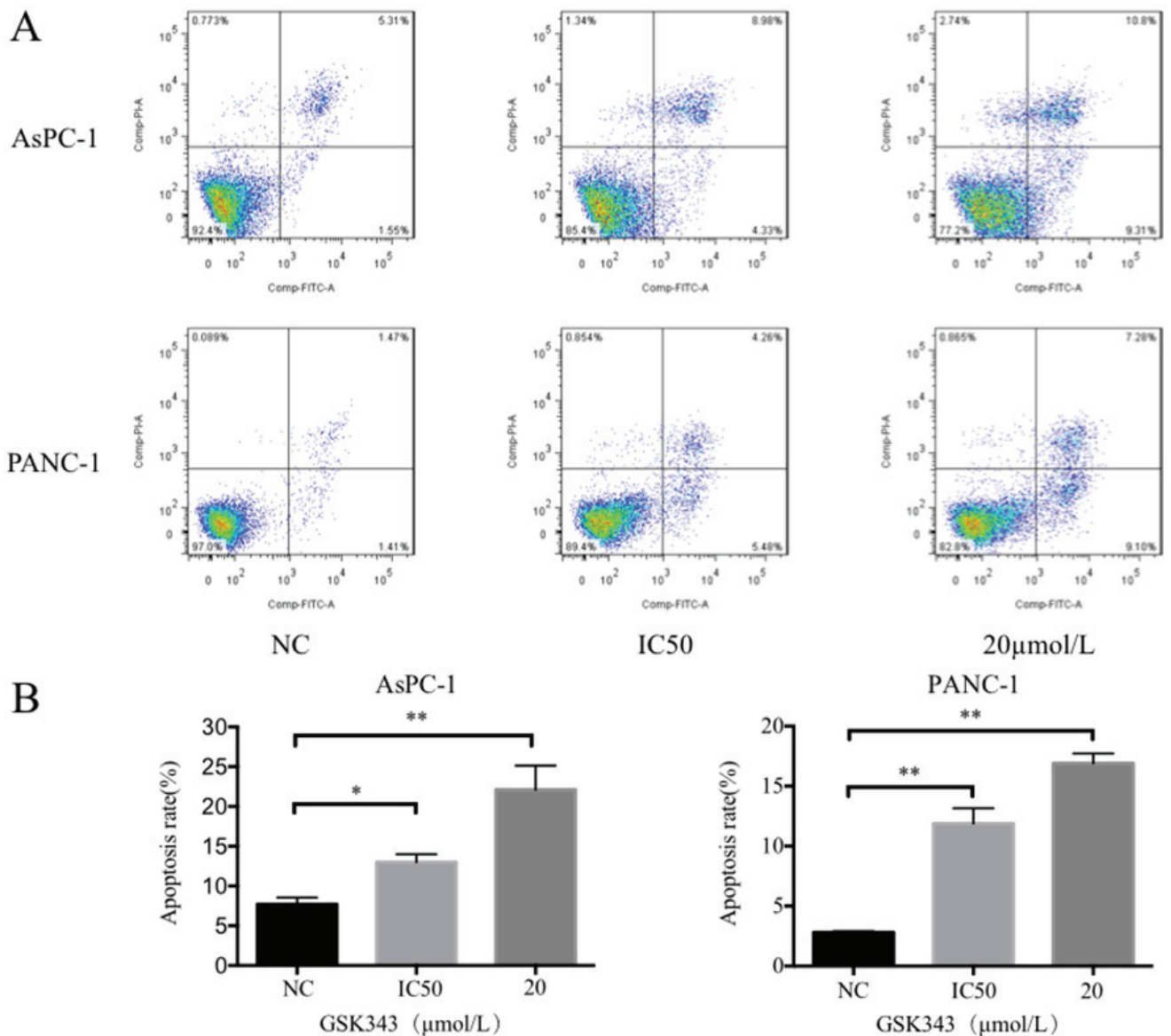

IC50

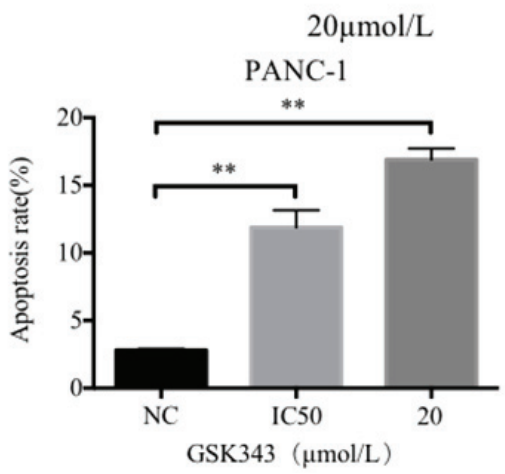

Figure 3. GSK343 promoted the apoptosis of AsPC-1 and PANC-1 cells. (A) Apoptotic AsPC-1 and PANC-1 cells were detected by Annexin V/PI double-stained flow cytometry after treatment with $0 \mu \mathrm{mol} / 1$, IC50, or $20 \mu \mathrm{mol} / 1 \mathrm{GSK} 343$ for $48 \mathrm{~h}$. (B) Apoptosis rates of AsPC-1 and PANC-1 cells are presented as the mean \pm standard deviation, ${ }^{*} \mathrm{P}<0.05$ and ${ }^{* *} \mathrm{P}<0.01$. NC, negative control.

immunofluorescence for microtubule-associated protein 1 light chain 3 (LC3) positive punctate dots in GSK343 treatments. As presented in Fig. 5A, LC3B punctate dots per cell (indicated by the red arrow) were markedly increased after GSK343 (IC50) treatment.

LC3 has been considered to be a crucial component in the elongation and closure of autophagosome membranes. Accompanied with this process, LC3 is converted from LC3-I to LC3-II (33). Therefore, autophagy was assessed using the LC3-II/LC3-I ratio (34). In Fig. 5B, following GSK343 (IC50) treatment, a reduction of LC3B-I in AsPC-1 cell was exhibited, but no significant change was observed in PANC-1 cells. However, LC3B-II was markedly increased in both cell types. Western blot analysis revealed that GSK343 (IC50) treatment significantly increased the ratio of LC3B-II/LC3B-I in AsPC-1 and PANC-1 cells (Fig. 5C).

ATG5, which can form the Atg12-Atg5-Atg16L complex, is also the crucial component of the ubiquitin-like conjugation system and promotes autophagosome formation (35). ATG5 did not reveal any significant change after treatment with GSK343 (IC50) in AsPC-1 or PANC-1 cell lines (Fig. 5B).

GSK343 inhibits the AKT/mTOR signaling pathway. The AKT/mTOR signaling pathway is reported to be activated in a variety of different types of cancer and negatively regulates autophagy (36). To identify the underlying signaling mechanism responsible for GSK343-induced autophagy, the role of the AKT/mTOR signaling pathway was investigated using western blot analysis. As presented in Fig. 6A and B, a marked reduction was observed in AKT and p-AKT results revealed a significant decrease in pancreatic cancer cells. Similarly, although the total mTOR level was variable in treated cells, p-mTOR was significantly reduced after GSK343 (IC50) treatment. The results indicate that GSK343 may downregulate the AKT/mTOR-mediated signaling pathway.

\section{Discussion}

EZH2 has been demonstrated to be highly expressed in malignant tumors, serving a crucial role in the progression of breast, bladder and liver malignancies (19-21). Therefore, inhibitors of EZH2 are of therapeutic interest in cancer research. Distinct from DZNep, a classic EZH2 inhibitor that decreases SAH, GSK343 suppresses EZH2 by competitively binding to a methyl donor, SAM $(17,18)$. In the present study, a significant dose and time-dependent reduction in the cell viability of pancreatic cancer cells by GSK343 was demonstrated. GSK343 also suppressed cell proliferation, induced cell apoptosis and blocked cell cycle progression at the G1-phase. These results are consistent with observations in a variety of different types of cancer and may help to identify a novel therapeutic approach for pancreatic cancer. 
A
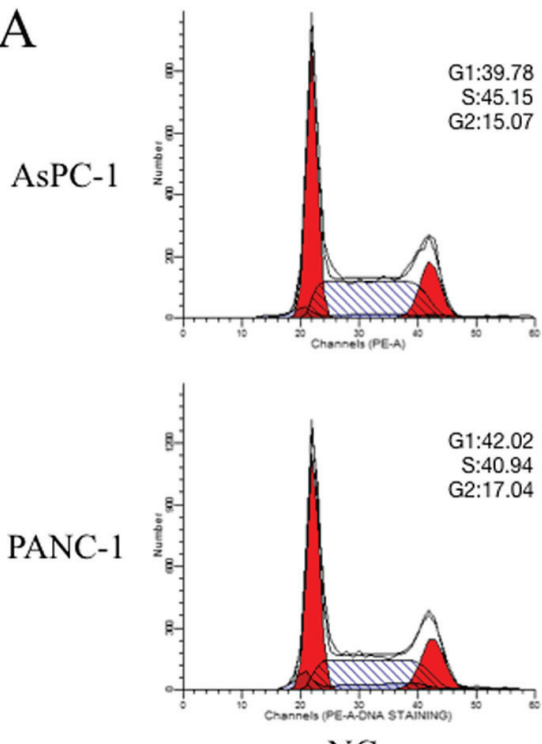

$\mathrm{NC}$
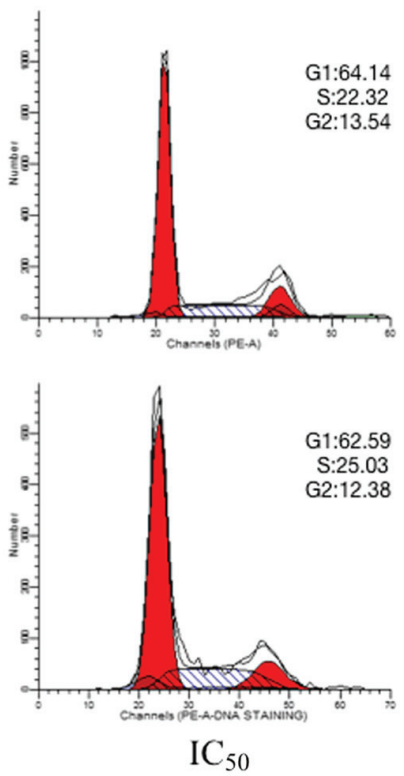
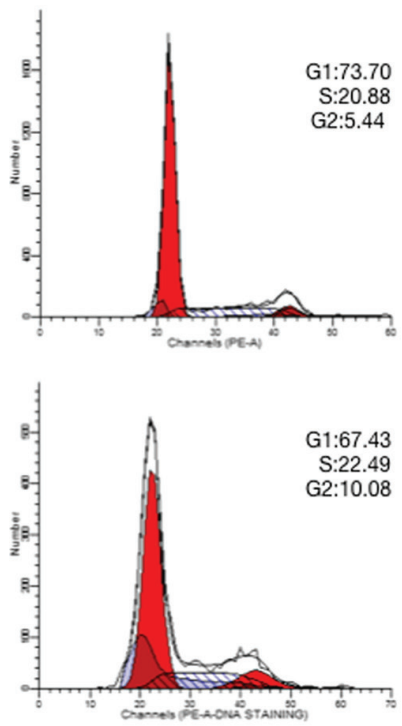

$20 \mu \mathrm{mol} / 1$

B
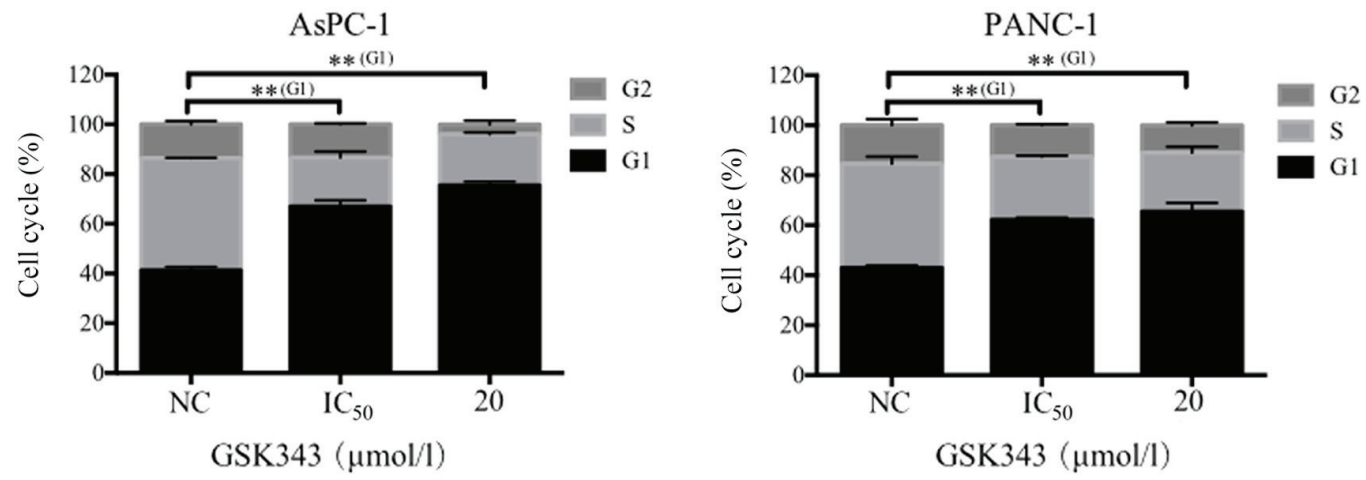

Figure 4. GSK343 induced cell cycle arrest in the G1 phase of AsPC-1 and PANC-1 cells. (A) Flow cytometry analysis was used to detect cell cycle distribution after treatment with $0 \mu \mathrm{mol} / 1$, IC50 and $20 \mu \mathrm{mol} / 1$ GSK343. (B) Percentage of AsPC-1 and PANC-1 cells in G1-S-G2-phase are presented as the mean \pm standard deviation, ${ }^{* *} \mathrm{P}<0.01$. NC, negative control.

Autophagy is an important cellular process that digests endogenous proteins or organelles via lysosomal degradation and is divided into macroautophagy, microautophagy and chaperone-mediated autophagy (37). Several studies have established that autophagy serves a crucial role in cell development and in the maintenance of homeostasis $(37,38)$. While autophagy can recycle damaged and/or dysfunctional cellular components (organelles and macromolecules) to provide raw materials for cell reconstruction and regeneration, the excessive upregulation of autophagy may result in autophagic cell death, also called type II programmed cell death $(38,39)$. mTOR, a highly evolutionarily conserved protein kinase, serves a key role in regulating autophagy and may be associated with epigenetic regulatory mechanisms $(40,41)$. In the present study, the GSK343 induced autophagy of pancreatic cancer cells was observed using immunofluorescence microscopy and western blot analysis. Although GSK343 induces autophagy in pancreatic cancer, as a direct and selective inhibitor of EZH2, whether EZH2 serves a role in GSK343-induced autophagy is controversial. A previous study demonstrated that EZH2 inhibited autophagy by epigenetically repressing the mTOR signaling pathway (42). However, a previous report also demonstrated that DZNep could not induce autophagy in breast, lung and hepatocellular carcinoma cells, and that the suppression of EZH2 expression was unnecessary for GSK343 to induce autophagy (30). The knockdown of EZH2 by small interfering RNA cannot induce autophagy sufficiently and its overexpression is unable to reduce autophagy, which is induced by EZH2 inhibitors in human colorectal cancer cells (31). GSK343-induced autophagy may be associated with the non-canonical pathway-mediated transcriptional upregulation of LC3B (31). These contrasting results require further investigation into the signaling mechanisms which govern the GSK343 induction of autophagy in a variety different types of cancer.

The AKT/mTOR signaling pathway is activated in different types of cancer and is a critical cellular pathway. Upstream AKT kinase can repress the Tuberous Sclerosis complex (TSC) $1 / 2$ by phosphorylating TSC 2 to promote mTOR activity, which regulates cell proliferation, differentiation, apoptosis and metabolism, and inhibits autophagy (40). In the current study, the mechanism of GSK343-induced autophagy in pancreatic cancer cells was investigated. Western blot analysis revealed a reduction in p-AKT and p-mTOR after GSK343 treatment. These results indicated that GSK343-induced autophagy involved the AKT/mTOR-mediated signaling pathway in pancreatic cancer cells. However, the role of GSK343 in the inhibition of the AKT pathway is unclear. A previous study 


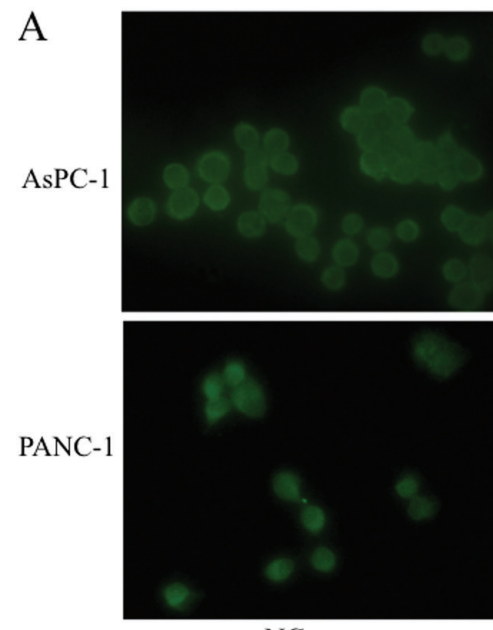

$\mathrm{NC}$
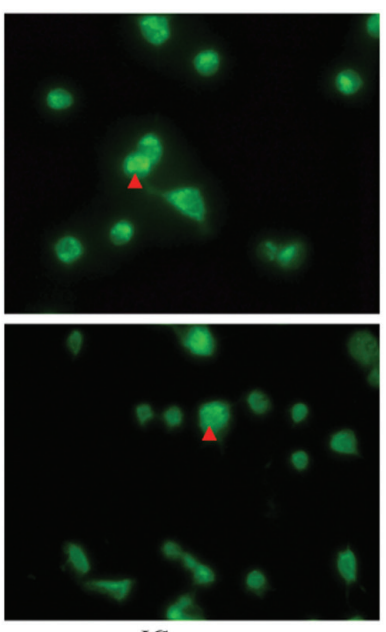

$\mathrm{IC}_{50}$
B

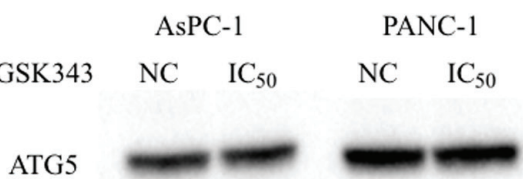

ATG5

LC3B-I

LC3B-II

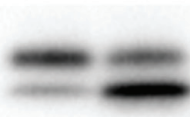

GAPDH

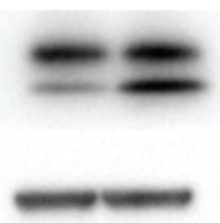

$\mathrm{C}$
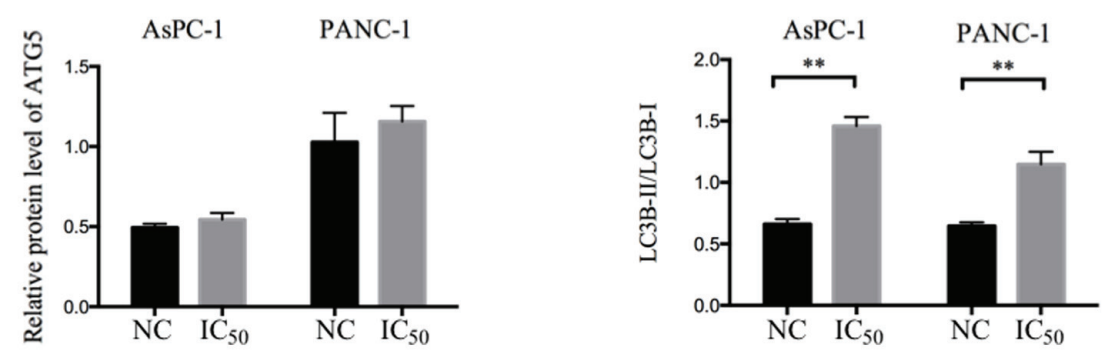

Figure 5. GSK343 induced autophagy in pancreatic cancer cells. (A) Autophagy induction was observed by immunofluorescence microscopy (red arrows indicate LC3B puncta; magnification, x400) after GSK343 (IC50) treatment for $48 \mathrm{~h}$. (B) Proteins extracted from AsPC-1 and PANC-1 cells treated with GSK343 (IC50) were analyzed using western blot analysis with the (C) subsequent quantification of western blotting results of ATG5 and LC3B, *"P<0.01. ATG5, autophagy-related protein 5; LC3B, microtubule-associated protein 1 light chain 3 beta; NC, negative control.

A

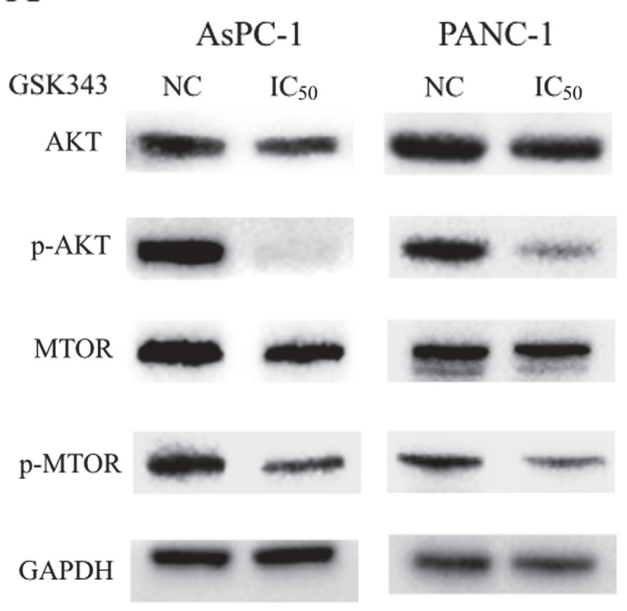

B AsPC-1 PANC-1
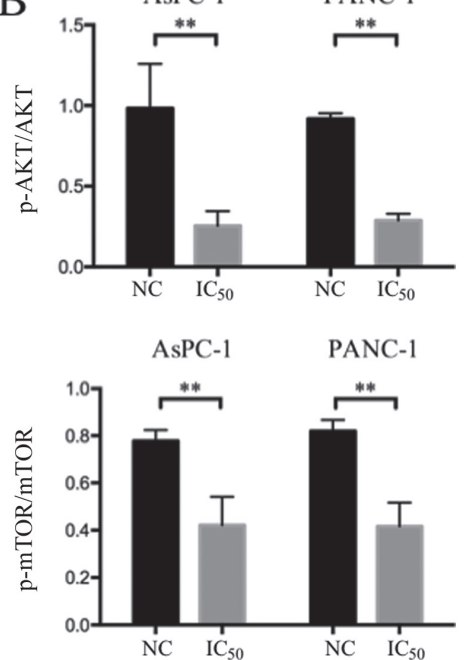

Figure 6. GSK343 inhibited the AKT/mTOR signaling pathway in AsPC-1 and PANC-1 cells. (A) Proteins extracted from cells treated with GSK343 (IC50) were analyzed by western blotting using primary antibodies against AKT, p-AKT, mTOR, p-mTOR and GAPDH with the (B) subsequent quantification of AKT, p-AKT, mTOR and p-mTOR, ${ }^{* *} \mathrm{P}<0.01$. P, phosphorylated; NC, negative control.

has revealed that increasing EZH2 can influence H3K27me3 and DNA methylation across the promoter to silence phosphatase and tensin homolog deleted on chromosome 10, which dephosphorylates phosphatidylinositol 3,4,5-triphosphate to inactivate AKT and mTOR complex 1 (43). Studies have also revealed that EZH2 inhibitors may induce endoplasmic reticulum stress, which negatively regulates the AKT/TSC/mTOR pathway to enhance autophagy $(31,44)$. Further experiments should be performed to support the mechanism of GSK343-induced autophagy in pancreatic cancer.

\section{Acknowledgements}

Not applicable. 


\section{Funding}

The present study was supported by the National Natural Science Foundation of China (grant nos.81572307 and 81773096) and the Major Project of Medical and Health Technology Development Program in Zhejiang Province (grant no. 7211902).

\section{Availability of data and materials}

The datasets used and/or analyzed during the present study are available from the corresponding author on reasonable request.

\section{Authors' contributions}

HX and LZ designed the present study. HX conducted the experiments, analyzed the data and drafted the manuscript. XQ, YY and JZ performed cell culture and flow cytometry analysis. XZ performed immunofluorescence microscopy. WG and MA conducted the western blot analysis. WW conceived the current study, and drafted and revised the manuscript. All authors have read and approved the final manuscript.

\section{Ethics approval and consent to participate}

Not applicable.

\section{Patient consent for publication}

Not applicable.

\section{Competing interests}

The authors declare that they have no competing interests.

\section{References}

1. Siegel RL, Miller KD and Jemal A: Cancer statistics, 2019. CA Cancer J Clin 69: 7-34, 2019.

2. Rahib L, Smith BD, Aizenberg R, Rosenzweig AB, Fleshman JM and Matrisian LM: Projecting cancer incidence and deaths to 2030: The unexpected burden of thyroid, liver, and pancreas cancers in the United States. Cancer Res 74: 2913-2921, 2014.

3. Vincent A, Herman J, Schulick R, Hruban RH and Goggins M: Pancreatic cancer. Lancet 378: 607-620, 2011.

4. Margueron R and Reinberg D: The Polycomb complex PRC2 and its mark in life. Nature 469: 343-349, 2011.

5. Di Croce L and Helin K: Transcriptional regulation by Polycomb group proteins. Nat Struct Mol Biol 20: 1147-1155, 2013.

6. Bracken AP, Pasini D, Capra M, Prosperini E, Colli E and Helin K: EZH2 is downstream of the pRB-E2F pathway, essential for proliferation and amplified in cancer. EMBO J 22: 5323-5335, 2003.

7. Sauvageau M and Sauvageau G: Polycomb group proteins: Multi-faceted regulators of somatic stem cells and cancer. Cell Stem Cell 7: 299-313, 2010.

8. Croonquist PA and Van Ness B: The polycomb group protein enhancer of zeste homolog 2 (EZH 2) is an oncogene that influences myeloma cell growth and the mutant ras phenotype. Oncogene 24: 6269-6280, 2005.

9. Varambally S, Dhanasekaran SM, Zhou M, Barrette TR, Kumar-Sinha C, Sanda MG, Ghosh D, Pienta KJ, Sewalt RG, Otte AP, et al: The polycomb group protein EZH2 is involved in progression of prostate cancer. Nature 419: 624-629, 2002.

10. Kleer CG, Cao Q, Varambally S, Shen R, Ota I, Tomlins SA, Ghosh D, Sewalt RG, Otte AP, Hayes DF, et al: EZH2 is a marker of aggressive breast cancer and promotes neoplastic transformation of breast epithelial cells. Proc Natl Acad Sci USA 100: 11606-11611, 2003.
11. Chien YC, Liu LC, Ye HY, Wu JY and Yu YL: EZH2 promotes migration and invasion of triple-negative breast cancer cells via regulating TIMP2-MMP-2/-9 pathway. Am J Cancer Res 8: 422-434, 2018.

12. Bachmann IM, Halvorsen OJ, Collett K, Stefansson IM, Straume O, Haukaas SA, Salvesen HB, Otte AP and Akslen LA: EZH2 expression is associated with high proliferation rate and aggressive tumor subgroups in cutaneous melanoma and cancers of the endometrium, prostate, and breast. J Clin Oncol 24: 268-273, 2006

13. Zingg D, Debbache J, Peña-Hernández R, Antunes AT, Schaefer SM, Cheng PF, Zimmerli D, Haeusel J, Calçada RR, Tuncer E, et al: EZH2-mediated primary cilium deconstruction drives metastatic melanoma formation. Cancer Cell 34: 69-84. e14, 2018.

14. Nakagawa M and Kitabayashi I: Oncogenic roles of enhancer of zeste homolog 1/2 in hematological malignancies. Cancer Sci 109: 2342-2348, 2018.

15. Ougolkov AV, Bilim VN and Billadeau DD: Regulation of pancreatic tumor cell proliferation and chemoresistance by the histone methyltransferase enhancer of zeste homologue 2. Clin Cancer Res 14: 6790-6796, 2008.

16. Maftouh M, Avan A, Funel N, Paolicchi E, Vasile E, Pacetti P, Vaccaro V, Faviana P, Campani D, Caponi S, et al: A polymorphism in the promoter is associated with EZH2 expression but not with outcome in advanced pancreatic cancer patients. Pharmacogenomics 15: 609-618, 2014.

17. Verma SK, Tian X, LaFrance LV, Duquenne C, Suarez DP, Newlander KA, Romeril SP, Burgess JL, Grant SW, Brackley JA, et al: Identification of potent, selective, cell-active inhibitors of the histone lysine methyltransferase EZH2. ACS Med Chem Lett 3: 1091-1096, 2012.

18. Glazer RI, Hartman KD, Knode MC, Richard MM, Chiang PK, Tseng CK and Marquez VE: 3-Deazaneplanocin: A new and potent inhibitor of S-adenosylhomocysteine hydrolase and its effects on human promyelocytic leukemia cell line HL-60. Biochem Biophys Res Commun 135: 688-694, 1986.

19. Raaphorst FM, Meijer CJ, Fieret E, Blokzijl T, Mommers E, Buerger H, Packeisen J, Sewalt RA, Otte AP and van Diest PJ: Poorly differentiated breast carcinoma is associated with increased expression of the human polycomb group EZH2 gene. Neoplasia 5: 481-488, 2003.

20. Raman JD, Mongan NP, Tickoo SK, Boorjian SA, Scherr DS and Gudas LJ: Increased expression of the polycomb group gene, $\mathrm{EZH} 2$, in transitional cell carcinoma of the bladder. Clin Cancer Res 11: 8570-8576, 2005.

21. Sudo T, Utsunomiya T, Mimori K, Nagahara H, Ogawa K, Inoue $\mathrm{H}$, Wakiyama S, Fujita $\mathrm{H}$, Shirouzu $\mathrm{K}$ and Mori M: Clinicopathological significance of EZH2 mRNA expression in patients with hepatocellular carcinoma. Br J Cancer 92: 1754-1758, 2005.

22. Chen Y, Xie D, Yin Li W, Man Cheung C, Yao H, Chan CY, Chan CY, Xu FP, Liu YH, Sung JJ and Kung HF: RNAi targeting EZH2 inhibits tumor growth and liver metastasis of pancreatic cancer in vivo. Cancer Lett 297: 109-116, 2010.

23. Matsukawa Y, Semba S, Kato H, Ito A, Yanagihara K and Yokozaki H: Expression of the enhancer of zeste homolog 2 is correlated with poor prognosis in human gastric cancer. Cancer Sci 97: 484-491, 2006.

24. Tan J, Yang X, Zhuang L, Jiang X, Chen W, Lee PL, Karuturi RK, Tan PB, Liu ET and Yu Q: Pharmacologic disruption of Polycomb-repressive complex 2-mediated gene repression selectively induces apoptosis in cancer cells. Genes Dev 21: 1050-1063, 2007.

25. Hirukawa A, Smith HW, Zuo D, Dufour CR, Savage P, Bertos N, Johnson RM, Bui T, Bourque G, Basik M, et al: Targeting EZH2 reactivates a breast cancer subtype-specific anti-metastatic transcriptional program. Nat Commun 9: 2547, 2018.

26. Wang J, Ai Z, Chen J, Teng Y and Zhu J: Enhancer of zeste homolog 2 blockade by RNA interference is implicated with inhibited proliferation, invasion and promoted apoptosis in endometrial carcinoma. Oncol Lett 15: 9429-9435, 2018.

27. Jones BA, Varambally S and Arend RC: Histone methyltransferase EZH2: A therapeutic target for ovarian cancer. Mol Cancer Ther 17: 591-602, 2018.

28. Mohammad F, Weissmann S, Leblanc B, Pandey DP, Højfeldt JW, Comet I, Zheng C, Johansen JV, Rapin N, Porse BT, et al: EZH2 is a potential therapeutic target for H3K27M-mutant pediatric gliomas. Nat Med 23: 483-492, 2017. 
29. Wang W, Xie Q, Zhou X, Yao J, Zhu X, Huang P, Zhang L, Wei J, Xie H, Zhou L and Zheng S: Mitofusin-2 triggers mitochondria $\mathrm{Ca} 2+$ influx from the endoplasmic reticulum to induce apoptosis in hepatocellular carcinoma cells. Cancer Lett 358: 47-58, 2015.

30. Liu TP, Lo HL, Wei LS, Hsiao HH and Yang PM: S-Adenosyl-L-methionine-competitive inhibitors of the histone methyltransferase EZH2 induce autophagy and enhance drug sensitivity in cancer cells. Anticancer Drugs 26: 139-147, 2015.

31. Hsieh YY, Lo HL and Yang PM: EZH2 inhibitors transcriptionally upregulate cytotoxic autophagy and cytoprotective unfolded protein response in human colorectal cancer cells. Am J Cancer Res 6: 1661-1680, 2016.

32. Xiong X, Zhang J, Liang W, Cao W, Qin S, Dai L, Ye D and Liu Z: Fuse-binding protein 1 is a target of the EZH2 inhibitor GSK343, in osteosarcoma cells. Int J Oncol 49: 623-628, 2016.

33. Klionsky DJ, Abdelmohsen K, Abe A, Abedin MJ, Abeliovich H, Acevedo Arozena A, Adachi H, Adams CM, Adams PD, Adeli $\mathrm{K}$, et al: Guidelines for the use and interpretation of assays for monitoring autophagy (3rd edition). Autophagy 12: 1-222, 2016.

34. Kabeya Y, Mizushima N, Ueno T, Yamamoto A, Kirisako T, Noda T, Kominami E, Ohsumi Y and Yoshimori T: LC3, a mammalian homologue of yeast Apg8p, is localized in autophagosome membranes after processing. EMBO J 19: 5720-5728, 2000.

35. Mizushima N, Noda T, Yoshimori T, Tanaka Y, Ishii T, George MD, Klionsky DJ, Ohsumi M and Ohsumi Y: A protein conjugation system essential for autophagy. Nature 395: 395-398, 1998.

36. Zhao GS, Gao ZR, Zhang Q, Tang XF, Lv YF, Zhang ZS, Zhang Y, Tan QL, Peng DB, Jiang DM and Guo QN: TSSC3 promotes autophagy via inactivating the Src-mediated PI3K/Akt/mTOR pathway to suppress tumorigenesis and metastasis in osteosarcoma and predicts a favorable prognosis. J Exp Clin Cancer Res 37: 188, 2018.
37. Mizushima N and Komatsu M: Autophagy: Renovation of cells and tissues. Cell 147: 728-741, 2011.

38. Mizushima N: A brief history of autophagy from cell biology to physiology and disease. Nat Cell Biol 20: 521-527, 2018.

39. Berry DL and Baehrecke EH: Autophagy functions in programmed cell death. Autophagy 4: 359-360, 2008.

40. Hay N and Sonenberg N: Upstream and downstream of mTOR. Genes Dev 18: 1926-1945, 2004

41. Kim J, Kundu M, Viollet B and Guan KL: AMPK and mTOR regulate autophagy through direct phosphorylation of Ulk1. Nat Cell Biol 13: 132-141, 2011.

42. Wei FZ, Cao Z, Wang X, Wang H, Cai MY, Li T, Hattori N, Wang D, Du Y, Song B, et al: Epigenetic regulation of autophagy by the methyltransferase EZH2 through an MTOR-dependent pathway. Autophagy 11: 2309-2322, 2015.

43. Jarome TJ, Perez GA, Hauser RM, Hatch KM and Lubin FD: EZH2 methyltransferase activity controls pten expression and mTOR signaling during fear memory reconsolidation. J Neurosci 38: 7635-7648, 2018.

44. Qin L, Wang Z, Tao L and Wang Y: ER stress negatively regulates AKT/TSC/mTOR pathway to enhance autophagy. Autophagy 6: 239-247, 2010.

(i) () $\odot$ This work is licensed under a Creative Commons

EY NO NO Attribution-NonCommercial-NoDerivatives 4.0 International (CC BY-NC-ND 4.0) License. 